\title{
Somogy megye dögbogár, sutabogár és lemezescsápú bogár faunája (Coleoptera: Silphidae, Histeridae, Lamellicornia)
}

\author{
ROZNER GYÖRGY
}

\begin{abstract}
ROZNER Gy:: Carrion, steel and lamellicom beetle fauna of Somogy county (Coleoptera: Silphidae, Histeridae, Lamellicornia)

Abstract: The entomological investigations in Somogy county started in the second half of the 1800 's. Thanks to the devoted efforts of many researchers, the following checklist gives an excellent representation of the rich fauna of the area. According to the data available, Somogy county is considered to be a well investigated area. In Somogy county, 65\% of the Silphidae, 58\% of the Histeriade, and $75 \%$ of the Lamellicornia fauna of Hungary have been recorded so far.
\end{abstract}

\section{Bevezetés}

Az elmúlt években, mind a rovartannal foglalkozó szakemberek között, mind az eredményeiket hasznosító szervezetek részéról, megnótt az igény olyan összefoglaló jellegú munkák iránt, melyek egy kisebb-nagyobb terület faunáját listaszerúen közlik, feldolgozva az addigi kutatások eredményeit.

Az általam tárgyalt bogár családok kutatása Somogy megyében három szakaszra osztható. Az elsố szakasznak a XIX. század második felétól az 1930-as évekig terjedő idôszakot tekinthetjük, melyben csak néhány kutató tevékenykedett a területen, ám az általuk összegyúitött adatok mennyisége figyelemre méltó. A legrégebbi egyben legvitatottabb kutató az 1800-as évek végén, Siófokon élő Lichtneckert Ferenc volt. Bár az általa gyúitött bogarak mindmáig megtalálhatóak a Magyar Természettudományi Múzeumban, azok pontos lelóhelye nem megállapítható a hiányos cédulázás miatt, így néhány faj tényleges előfordulása a megyében kérdéses. A késóbbiekben Ehmann Ferenc, majd Wachsmann Ferenc nevét kell kiemelnünk, akik munkásságukkal jelentôs mértékben hozzájárultak a megye faunájának megismeréséhez.

A kutatások második korszaka az 1950-es 70-es éveket felöleló idószak, melyet a rendszertelen, alkalmi gyúitések jellemeznek. A területen megforduló kutatók közül a teljesség igénye nélkül, Dr. Lenczy Rudolf, Dr. Kaszab Zoltán, Dr. Kovács László nevét kell említenünk, akik sok értékes adattal bóvítették ismereteinket. Külön meg kell emlékeznünk, a többiektốl eltérően, a megyében élő Nattán Miklósról. Bár lepkékkel foglalkozott elsősorban, sok bogarat is gyújtött Kaposvár környékén. Munkajjának jelentôségét növeli, hogy azon a területen mindmáig nem történt átfogó kutatás.

A 90-es években a kutatások új lendületet kaptak, és ezzel elérkeztünk a máig is tartó harmadik korszakhoz. A Duna-Dráva Nemzeti Park megalakulása szükségessé tette a terület alaposabb megismerését, biológiai állapotának felmérését. További igényként jelentkezett más védett területek faunisztikai és ökológiai vizsgálata is, és a kutatások megvalósítására szervezett programok sok amatôr és hivatásos rovarászt mozgattak meg. Az általuk összegyúijtött adatok átfogó képet adnak az érintett területek rovarfaunájáról. 


\section{Somogyban elóforduló fajok listája}

Silphidae

Necrophorus humator (liviex, 1790) - Merkl 1998

Necrophorus fossor Erichson, 1837 -

Székessy 1961, Merkl 1998

Necrophorus vespilloides Herbst, 1784. -

Merkl 1998

Necrophorus vespillo (Linncaus, 1758) -

Merkl 1998

Necrophorus vestigator Hersch. - Szćkessy 1961

Necrodes litoralis (Linneaus, 1758) - Merkl 1998

Thanatophilus rugosus (Linneaus, 1758) -

Merkl 1998

Thanatophilus sinuatus (Fabricius, I775) -

Merkl 1998

Oeceoptoma thoracicum (Linneaus, 1758) -

Merkl 1998

Xylodrepa quadripunctata (Linncaus, 1758) -

Merkl 1998

Silpha carinata Herbst, 1783 - Merkl 1998

Silpha obscura Linneaus, 1758 - Merkl 1998

Silpha tristis Illiger - coll. Rozner Gy.

Ablattaria laenigata (Fabricius, 1775).

Merkl 1998

Phosphuga atrata (Linneaus, 1758) - Merkl 1998

Agyrtes bicolor Castelnau, 1840 - Merkl 1998

Histeridae

Abraeus granulum Erichson, 1839 - Mazur et

Kaszab 1980)

Abraeus perpusillus (Marsham, 1802) -

Merkl 1998

Abraeus roubali Olexa, 1958 - Mazur et

Kaszab 1980, coll. Rozner Gy.

Plegaderus saucius Erichson, 1839 - Mazur

ct Kašab 1980)

Eubrachium pusillum (Rossi, 1792) - Mazur

et Kaszab 1980

Acritus minutus (Herbst, 1792) - Merkl 1998

Acritus homoeopathicus Wollaston, 1857 .

Merkl 1998

Aeletes atomarius (Aubé, 1842) - Mazur et

Kaszab 1980

Teretrius fabricii Mazur, 1972 - Mazur et

Kaszab 1980, Merkl 1998

Saprinus pharao Marseul, 1855 - Mazur et Kaszab 1980

Saprinus quadristriatus (Thunberg, 1794) -

Mazur et Kaszab 1980

Saprinus planiusculus Motschulsky, 1849 -

Merkl 1998

Saprinus semistriatus (Scriba, 1790) - Merkd

(1998), Sár 1992
Saprinus subnitescens Bickhardt, 1909 - coll.

Rozner Gy.

Saprinus furmus Erichson, 1834 - Mazur et Kaszab 1980

Saprinus georgicus Marseul, 1862 - coll. Rozner Gy.

Saprinus virescens (Paykull, 1798) - Mazur et Kaszab 1980

Saprinus cribellatus Marseul, 1855 - Mazur et Kaszab 1980

Saprinus aeneus (Fabricius, 1775) - Merkl 1998

Gnathoncus suturifer Reitter, 1896 - Mazur ct Kaszab 1980

Gnathoncus schmidti Reitter, 1894 - Mazur et Kaszab 1980

Chalcionellus decemstriatus (Rossi, 1792) coll. Rozner Gy.

Hypocacculus metallescens (Erichson, 1834) Mazur et Kaszab 1980

Hypocacculus curtus (Rosenhaver, 1847) Mazur et Kaszab 1980

Hypocaccus rugiceps (Duftschmid, 1805) Mazur et Kaszab 1980

Hypocaccus metallicus (Herbst, 1792) Mazur el Kaszab 1980)

Exaesiopus grossipes (Marseul, 1855) - Mazur et Kaszab 1980

Dendrophilus punctatus (Herbst, 1792) Merkl 1998

Dendrophilus pygmeus (Linnaeus, 1758) Mazur et Kaszab 1980, Merkl 1998

Carcinops pumilio (Erichson, 1834) - Mazur et Kaszab 1980, Merkl 1998

Paromalus parallelepipedus (Herbst, 1792) Sár 1992, Merkl 1998

Paromalus flavicomis (Herbst, 1792) - Sár 1992, Merkl I998

Onthophilus punctatus (O. F. Müller, 1776) Merkl 1998

Onthophilus striatus (Forster, 1771) - coll. Rozner Gy

Onthophilus affinis Redtenbacher, 1849 Merkl 1998 1998

Epierus comptus Erichson, 1834 - Merkl

Pseudepierus italicus (Paykull, 1811) - Mazur el Kaszab 1980

Pachylister inaequalis (Olivier, 1789) - coll. Rozner Gy.

Hister quadrimaculatus Linnacus, 1758 MerkJ 1998 
Hister unicolor Linnaeus, 1758 - Merkl 1998 Hister quadrinotatus Scriba, 1790 - coll. Rozner Gy.

Hister uncinatus Illiger, 1807 - coll. Rozner Gy Hister lugubris Truqui, 1852 - Mazur et Kaszab 1980

Hister bissexstriatus Fabricius, 1801 - coll. Rozner Ciy.

Margarinotus brunneus (Fabricius, 1775) Merkl 1998

Margarinotus striola (Sahlberg, 1834) ssp. succicola (1homson, 1862) - Mazur et Kaszab 1980

Margarinotus purpurascens (Herbst, 1792) Sár 1992

Margarinotus neglectus (Germar, I813) coll. Rozner Gy.

Margarinotus punctiventer (Marseul, 1854) Merkl 1998

Margarinotus carbonarius (Hoffmann, 1803) coll. Rozner Cry.

Margarinotus ruficonis (Grimm, 1852) Mazur et Kaszab 1980, coll. Rozner Gy.

Margarinotus stercorarius (Hoffmann, 1803) coll. Rozner Gy.

Atholus duodecemstriatus (Schrank, 1782) ssp. quatuordecemstriatus (Gyllenhal, 1808) Merkl 1998

Hololepta plana (Sulzer, 1776) - Merkl 1998 Platysoma frontale (Paykull, 1798) - Merkl 1998

Platysoma compressum (Herbst, 1783) - coll. Rozner Gy.

Cylister lineare (Erichson, 1834) - Mazur et Kaszab 1980

Cjlister elongatum (1hunberg, 1787) - Merkl 1998

Hetaerius fentugineus (Olivier, 1789) - Merkl 1998

\section{LAMELLICORNIA}

Lucanidae

Lucanus cervus (Linneaus, 1758) - Endrôdi 1957, Sár 1992, Sár 1995, Sár 1998

Dorcus parallelepipedus (Linnaeus, 1758) Endródi 1957, Sár 1992, Sár 1998

Platycerus caraboides (Linnacus, 1758) =cribratus (Mulsant et Rey, 1863) - Endródi 1957, Sár (1998)

Aesalus scaraboides (Panzer, 1794) - Endrödi 1957, Sár (1998)

\section{Trogidae}

Trox sabulosus (Linnaeus, 1758) - Endrödi 1957, Sár 1995, Sár (1998)

Trox hispidus (Pontoppidan, 1763) Endródi 1957, Sár 1995, Sár 1998

Trox Eversmanni Krynicky, 1832 - Endrödi 1957, Sár 1995
Trox cadaverinus Illiger, 1802 - Sár 1995

Trox scaber (Linnacus, 1767) - Endrödi 1957, Sár 1995

Trox perrisi Fairmaire, 1868 - Endrödi 1957, coll.: Rozner Gy.

\section{Glaresidae}

Glaresis rufa Erichson, 1848 - Endrôdi 1957, coll.: Rozner Gy.

\section{Geotrupidae}

Odontaeus armiger (Scoppoli, 1772) Endrődi 1957, Sár 1995, Sár 1998

Bolbelasmus unicomis (Schrank, 1789) Endrôdi 1957, coll.: Rozner Gy.

Geotrupes mutator (Marscham, 1802) -

Endrődi 1957, Sár 1998

Geotrupes spiniger (Marsham, 1802) -

Endródi 1957, Sár 1995, Sár (1998)

Geotrupes stercorarius (Linnaeus, 1758) Endrôdi 1957

Anoplotrupes stercorosus (Hartmann in L.G.Scriba, 1791) - Endrödi 1957, Sár 1992, Sár 1995, Sár (1998)

Trypocopris pernalis (Linnaeus, 1758) Endródi (1956), Endródi 1957, Sár 1992, Sár 1995, Sár (1998)

Lethrus apterus (Laxmann, 1770) - Endrödi 1957, coll.: Rozner Gy.

\section{Ochodaeidae}

Ochodaeus chrysomeloides (Schrank, 1781) Endrôdi 1957, Sár 1995

Cadocera ferrogineum Eschscholtz, 1818 Endrôdi 1957

\section{Scarabaeidae}

Scarabaeus puncticollis Latreille - Endrödi (1956), Endródi 1957

Gymnopleurus mopsus (Pallas, 1781) -

Endrödi 1957

Sisyphus Schafferi (Linnaeus, 1758) Endrődi 1957, coll.: Rozner Gy.

Copris lunaris (Linnaeus, I758) - Endródi 1957, Sár 1992, Sár 1995, Sár 1998

Oniticellus fulvus (Gocze, 1777) - Endrödi 1957, Sár 1998

Oniticellus pallipes (Fabricius, 1823) Endrödi 1957

Caccobius schreberi (Linnaeus, 1767) Endrödi 1957, coll.: Rozner Gy.

Euonthophagus amyntas alces (Fabricius, 1792) - Endródi 1957, Sár 1995

Onthophagus furcatus (Fabricius, 1781) Endródi 1957, coll.: Rozner Gy. 
Onthophagus gibbulus (Pallas, 178I).

Endrödi 1957, coll.: Rozner Gy.

Onthophagus fissicornis (Krynicky) - Endrödi

1956, Endródi 1957

Onthophagus fracticornis (Preyssler, 1790).

Endrődi 1957, Sár 1992

Onthophagus coenobita (Herbst, 1783).

Endrödi 1957, Sár 1995, Sár 1998

Onthophagus lemur (Fabricius, 178I) -

Endródi 1957, coll.: Rozner Gy.

Onthophagus lucidus (Sturm, 1800) - coll.:

Rozner Gy.

Onthophagus nuchicomis (Linnaeus, 1758) -

Endródi 1957

Onthophagus ovatus (Linnaeus, I767) -

Endródi 1957, Sár 1992, Sár 1995, Sár 1998

Onthophagus ruficapillus (Brullé, 1832) -

Endrơdi 1957, Sár 1992, Sár 1995, Sár 1998

Onthophagus semicomis (Panzer, 1798) -

Endrödi 1957, coll.: Rozner Gy.

Onthophagus vacca (Linnacus, 1767).

Endródi 1957, coll.: Rozner Gy.

Onthophagus verticicomis (Laicharting, 178I) -

Endródi 1957, Sár 1995

Onthophagus vitulus (Fabricius, 1776).

Endródi 1957, coll.: Rozner Gy.

Onthophagus illyricus (Scoppoli, 1763).

Endrődi 1957, Sár 1995

Onthophagus taurus (Schreber, 1759) -

Endrôdi I957, Sár 1995, Sár 1998

Aphodius scrutator (Herbsı, 1789) - Endródi

1957, Sár 1995

Aphodius subterraneus (Linnacus, 1758).

Endródi 1957, Sár 1992, Sár 1995, Sár 1998 Aphodius erraticus (Linnaeus, 1758).

Endrödi 1957, Sár 1995

Aphodius fossor (Linnaeus, 1758) - Endrödi

1957, Sár 1998

Aphodius haemorrhoidalis (Linnacus, 1758) -

Endrödi 1957, Sár 1998

Aphodius brevis (Erichson, I848) - coll.:

Rozner Gy.

Aphodius putridus (Fourcroy, 1785) - coll.:

Rozner Cry.

Aphodius depressus (Kugelann, 1792) - Sár

1995, Sár (1998)

Aphodius luridus (Fabricius, 1775) - Endrôdi

1957, coll.: Rozner Gy.

Aphodius rufipes (Linnaeus, 1758) - Sár

1995, Sár (1998)

Aphodius satellitius (Herbst, 1789) - Endródi 1957

Aphodius coenosus (Panzer, 1798) - coll.;

Rozner Gy.

Aphodius pusillus (Herbst, 1789) - Endrödi 1957, coll.: Rozner Gy.
Aphodius quadriguttatus (Herbst, 1783) -

Endrödi 1957, coll.: Rozner Gy.

Aphodius biguttatus Germar, 1824 - Endrődi

1957, Sár 1995

Aphodius quadrimaculatus (Linnaeus, 1761) -

Endrödi 1957, coll.: Rozner (ry.

Aphodius distinctus (O.F.Müller, 1776) -

Endrődi 1957, Sár 1995, Sár 1998

Aphodius melanostictus W.L.Schnide, I840 -

Endrödi 1957

Aphodius sticticus (Panzer, 1798) - Endrödi

1957, coll.: Rozner Gy.

Aphodius contaminatus (Herbst, 1783) -

Endrôdi 1957

Aphodius obliteratus Panzer, 1823 - Endrödi 1957

Aphodius circumcinctus W.L.Schmidt, 1840 -

Endrödi 1957

Aphodius consputus Creutzer, 1799 - Endrốdi

1957, coll.: Rozner Gy.

Aphodius prodromus (Brahm, 1790) .

Endrốdi 1957, Sár 1995, Sár 1998

Aphodius pubescens Sturm, 1800 - Endrôdi

1957, coll.: Rozner Gy.

Aphodius sphacelatus (Panzer, I798)

Endrốdi 1957, coll.: Rozner Gy.

Aphodius scrofa (Fabricius, 1787) - Endrôdi

1957, coll.: Rozner Gy.

Aphodius merdarius (Fabricius, 1775) -

Endrốdi 1957

Aphodius fimetarius (Linnaeus, 1758) -

Endrődi 1957, Sár 1995, Sár 1998

Aphodius foetens (Fabricius, 1787) - Endródi 1957

Aphodius foetidus (Herbst, I783) - Endrödi

1957, coll.: Rozner Gy.

Aphodius suarius Faldermann, 1836 -

Endrôdi (1956), Endródi 1957

Aphodius ater (De Geer, 1774) - Sár 1995

Aphodius uliginosus Hardy, 1847 - Endrödi

1957, Sár 1995

Aphodius ictericus (Laicharting, 1781).

Endrödi 1957, Sár 1995

Aphodius immundus Creutzer, 1799.

Endrödi 1957, Sár 1998

Aphodius lugens Creulzer, 1799 - Endródi 1957

Aphodius rufus (Moll, 1782) - Endródi

1957, Sár 1995

Aphodius sordidus (Fabricius, 1775) -

Endrö́di 1957, coll.: Rozner Gy.

Aphodius corvinus Erichson, 1848 - Endrödi 1957

Aphodius kraatzi Harold, 1868 - Endrődi 1957

Aphodius lividus (Olivier, 1789) - Endródi 1957

Aphodius niger (Panzer, 1797) - Endródi

1957, coll.: Rozner Gy.

Aphodius plagiatus (Linnaeus, 1767) -

Endródi 1957 
Aphodius sturmi Harold, 1870 - Endrōdi 1957 Aphodius varians Duftschmidt, 1805 . Endrö́di 1957, Sár 1995, Sár 1998

Aphodius granarius (Linnaeus, 1767) Endrödi 1957, Sár 1992, Sár 1995, Sár 1998

Heptaulacus testudinarius (Fabricius, 1775) -

Endrödi 1957

Euheptaulacus sus (Herbst in Füessly, 1783) .

Endrödi 1957

Oxyomus silvestris (Scoppoli, 1763).

Endrödi 1957, Sár 1998

Psammodius asper (Fabricius, I775) -

Endrődi 1957, Sár 1998

Psammodius pierottii Pittino, 1978 - Ádám 1993

Rhysemus germanus (Linnacus, 1767) -

Endrödi 1957, Sár 1998

Diastictus pulneratus (Sturm, 1805) -

Endródi 1957, coll.: Rozner Gy.

Pleurophorus caesus (Creutzer in Panzer, 1796) - Sár 1992, Sár 1995, Sár 1998

\section{Melolonthidae}

Serica brunnea (Linnaeus, 1758) - Endrődi 1957, Sár 1995, Sár 1998

Maladera holosericea (Scoppoli, 1772) -

Endródi 1957, Sár 1995

Omaloplia alternata occidentalis Baraud,

1965 - Endrődi 1957

Omaloplia ruricola (Fabricius, 1775) -

Endrődi 1957

Omaloplia marginata Füessl - Endrődi 1957

Omaloplia spiracae (Pallas, 1773) - Endrốdi

1957, Sár 1995

Rhizotrogus aestivus (Olivier, 1789).

Endrödi 1957, Sár 1995, Sár 1998

Miltotrogus aequinoctialis (Herbst, 1790) -

Endrődi 1957, Sár 1995, Sár (1998)

Miltotrogus pernus (Germar, 1823) - coll.:

Rozner Gy.

Miltotrogus pilicollis (Gyllenhall in Schönher,

1817) - Sár 1995

Amphimallon solstitiale (Linnaeus, 1758) -

Endrődi 1957, coll.: Rozner Gy.

Amphimallon assimile (Herbst, 1790) -

Endrődi 1957, Sár 1995

Anoxia orientalis Krynicky - Endrōdi 1957,

Sár 1995

Anoxia pillosa (Fabricius, 1792) - Endródi 1957, Sár 1992

Pholyphylla fullo (Linnaeus, 1758) - Endrôdi 1957, Sár 1992, Sár 1995

Melolontha melolontha (Linnaeus, 1758).
Endrődi 1957, Sár 1995, Sár 1998

Melolontha hippocastani Fabricius, 1801 -

Endrốdi 1957, Sár 1995

Anomala pitis (Fabricius, 1775) - Endródi

1957, Sár 1995, Sár 1998

Anomala dubia (Scoppoli, 1763) - Endrôdi

1957, Sár 1995

Phyllopertha horticola (Linnacus, 1758).

Endrôdi 1957, Sár 1995, Sár 1998

Chaetopteroplia segetum (Herbst, 1783) -

Endrödi 1957, Sár 1992, Sár 1995

Anisoplia austriaca (Herbst, 1783) - Endródi 1957

Anisoplia agricola (Poda, 1761) - Endrődi 1957

Anisoplia zwickii lata Erichson, 1847 . Endrödi 1957

Hoplia farinosa $($ Linnaeus, 1761) = philanthus auct nec.(Füessly, 1775) - Endrődi 1957, coll.: Rozner Gy.

Hoplia argentea $($ Poda, 1761) = farinosa auct. nec. (Linnaeus, 1761) - coll.: SM.Múzeum Kaposvár

Hoplia graminicola (Fabricius, 1792) -

Endrödi 1957

Hoplia hungarica Burmeister, 1844 . Endrődi 1957

Hoplia dilutipes (Reitter, 1890) - Endrôdi

1957, coll.: SM.Múzeum Kaposvár

Oryctes nasicornis holdhausi Minck, 1914 Endrôdi 1957, Sár 1995

Pentodon idiota (Herbst, 1789) - Endrödi 1957

Valgus hemipterus (Linnaeus, 1758) -

Endrôdi 1957, Sár 1998

Gnorimus variabilis (Linnaeus, 1758) - coll.:

Rozner Gy.

Trichius sexualis Bedel, 1906 - Sár 1995

Trichius fasciatus (Linnaeus, 1758) - Endródi 1957

Tropinota hirta (Poda, 1761) - Endrődi

1957, Sár 1995, Sár 1998

Oxythyrea funesta (Poda, 1761) - Endrödi

1957, Sár 1995, Sár 1998

Cetonia aurata aurata (Linnaeus, 1758) -

Endrödi 1957, Sár 1995, Sár 1998

Liocola lugubris (Herbst, 1786) - Endrödi 1957

Cetonischema aeruginosa (Drury, 1770) -

Endrődi 1957, Sár 1995

Eupotosia affinis (Andersch, 1794) - Endródi 1957

Potosia cuprea (Fabricius) - Endrődi 1957,

Sár 1995, Sár 1998

Potosia fieberi (Kraatz, 1880) - Endrődi 1957

Potosia hungarica (Herbst, 1792) - Endrôdi 1957, coll.: Rozner Gy. 


\section{Értékelés}

A rendelkezésre álló adatok alapján megállapíthatjuk, hogy Somogy megye a jobban kutatott területek közé tartozik. A hazai faunából a dögbogarak 65\%-a, sutabogarak 58\%-a, a lemezescsápú bogarak mintegy 75\%-a került elő eddig a megyéból. Ez jó aránynak tû́nik, de az adatok alaposabb vizsgálatakor észrevehetünk néhány problémát. Elsóként a már említett régi, elsốsorban a Lichtneckert féle adatok hitelessége, sok esetben vitatható. Másrészt az élóhelyek olyan mértékben változtak azóta, hogy számolnunk kell néhány faj eltúnésével is. Ezért az Endrődi Sebő által 1956-ban és 1957-ben közölt, és addig teljesnek tekinthetô adatok mellé, minden esetben feltüntettem azokat a még nem publikált adatokat is, melyek az utóbbi években megerôsítik a faj előfordulását.

A másik hiányosságot a kutatott területek aránytalan eloszlása jelenti. Jól kutatott területnek tekinthetjük a Balaton-part térségét, és a Dráva-mentét. Az érintett bogárcsaládok tekintetében csak szórványos adatokat találunk Kaposvár környékéról, és a Boronka-melléki TK területéról, így fehér foltnak számít a Somogyi-dombság, a Zselic, Belső-Somogy nagyobb része és a Marcali-hát. A további évek kutatásainak feladata, hogy ezekról a területekról képet adjon, és várakozásomnak megfelelően további fajok jelenlétét bizonyítsa.

\section{Köszönetnyilvánítás}

Ezen a helyen szeretnék köszönetet mondani mindazoknak, akik akár a múltban, akár napjainkban kutatásaikkal hozzájárultak Somogy megye faunájának megismeréséhez. Áldozatos munkájuk eredménye segíti a gyakorlati területeken dolgozó szakembereket.

Külön köszönetet mondok Ábrahám Leventének és Merkl Ottónak, akik szakmai segítséget nyújtottak dolgozatom elkészítésében, és lehetôséget adtak az általuk irányított gyújtemények tanulmányozására.

\section{I. táblázat: Somogy megyében kimutatott bogárfajok családonkénti száma}

\begin{tabular}{|l|c|c|}
\hline \multirow{2}{*}{ Család } & \multicolumn{2}{|c|}{ Fajok száma } \\
\cline { 2 - 3 } & Magyarországon & Somogy megyćben \\
\hline Silphidac & 25 & 16 \\
\hline Histeridac & 104 & 59 \\
\hline Lucanidae & 6 & 4 \\
\hline Trogidae & 6 & 6 \\
\hline Glaresidae & 1 & 1 \\
\hline Geotrupidae & 8 & 8 \\
\hline Ochodaeidae & 3 & 2 \\
\hline Scarabacidae & 115 & 80 \\
\hline Melolonthidac & 54 & 44 \\
\hline
\end{tabular}




\title{
Irodalom
}

ÁDর́M, L. 1993: Néhány újabb lemezescsápú bogár (Coleoptera: Scarabaeoidea) előfordulása a Kárpát-medencében -Folia ent. hung. 54: 163-189.

ENDRÓDI, S. 1956: Lemezescsápú bogarak (Lamellicornia) - Magyarország Állatvilága (Fauna Hungariae) IX./ 4.füzet, Akadémiai Kiadó, Budapest

ENIROỎDI, S. 1957: A lemezescsápú bogarak (Lamellicornia) Kárpát-medencei lelöhely adatai Rovartani Közlemények 10: 145-226.

MerkL, O. 1998: Data to 46 beetle families (Coleoptera) from the Duna-Dráva National Park, South Hungary - Dunántúli Dolgozatok Természettudományi Sorozat 9: 209-232.

Sর́r, J. 1992: Adatok a Boronka-melléki Tájvédelmi Körzet Bogárfaunájához (Coleoptera) Dunántúli Dolgozatok Természcttudományi Sorozat 7: 149-161.

Sák, J. 1995: Vizsgálatok a Dráva mente lemezescsápú bogár (Colcoptera: Lamellicornia) faunáján - Dunántúli Dolg. Term.tud. Sorozat 8./ 85-91, Pécs

Sár, J. 1998: Vizsgálatok a Dráva mente lemezescsápú bogár (Coleoptera: Lamellicornia) faunáján II. - Dunántúli Dolgozatok lermészettudományi Sorozat 9: 203-207.

SlAwomir, M. - Kuszab Z 1980): Sutabogarak (Histeridae) - Magyarország Állatvilága (Fauna Hungariae) VII. kötet 14. füzet, Akadémiai Kiadó, Budapest

SzÉKESSY, V. 1961: Holyvaalkatúak I. (Staphylinoidea I.) - Magyarország Állatvilága (Fauna Hungariae) VII. kötet, I füzet, Akadéniai Kiadó, Budapest

\section{Carrion, steel and lamellicorn beetle fauna of Somogy county (Coleoptera: Silphidae, Histeridae, Lamellicornia)}

\section{GYÖRGY ROZNER}

According to all the data available, the Histeridae family is the least known of all the beetle families, and more species of the Scarabaeidae family are expected to be found. The intensive research work started recently will hopefully expand our knowledge in this field. Since most of the available data come exclusively from the area near Lake Balaton and the area alongside the River Dráva, in the future, researches should concentrate mainly on the middle part of the county.

Since the voucher specimens in the Hungarian Natural History Museum (Budapest) are more than a hundred years old and their precise collecting sites are indefinable, the occurrence of certain species in Somogy county are doubtful. Future researches could provide answer for these questions as well.

\author{
Author's address: \\ György ROzNER \\ H-8693 Kisberény \\ Petőfi u. l. \\ HUNGARY
}

